TAO, Vol. 16, No. 3, 691-706, August 2005

\title{
To Construct an Effective Coefficient of Aerosol Size Distribution for Atmospheric Turbidity Retrieval
}

\author{
Tang-Huang Lin ${ }^{1, *}$, Gin-Rong Liu ${ }^{1,2}$ and Chih-Kang Liang ${ }^{1}$
}

(Manuscript received 30 November 2004, in final form 21 June 2005)

\begin{abstract}
Due to the complexity in the composition and variability of aerosols, it is difficult to employ a simple and straightforward physical model in calculating the coefficient $(\alpha)$ used to describe the size and distribution of aerosols in the absence of actual data. This problem complicates the already difficult retrieval of various atmospheric parameters from remotely sensed data. Thus, the main purpose of this study is to find an alternate effective aerosol size coefficient that can replace $\alpha$, and be stable under normal atmospheric conditions. Furthermore, this coefficient should be such that it can be employed in retrieving the atmospheric turbidity from satellite data when the value of $\alpha$ is unknown. This paper also strives to construct an "effective aerosol size coefficient" database for each respective season. Such a database could supply pertinent information on the atmosphere's opacity quickly and effectively.
\end{abstract}

(Key words: Atmospheric turbidity, Effective aerosol size coefficient, Air quality)

\section{INTRODUCTION}

Currently, through the observation of satellites, aerosol information can be provided both globally and locally serving as a very useful tool in monitoring the changes of our planet. The primary objective of this paper is how best to take advantage of satellite data in monitoring and analyzing the pressing environmental issue of air quality. Air quality parameters generally include: Ground-level ozone, particulate pollution, carbon monoxide, sulfur dioxide, and nitrogen dioxide. Particulate pollution is usually the main factor used in the assessment of air

\footnotetext{
${ }^{1}$ Center for Space and Remote Sensing Research, National Central University, Chung-Li, Taiwan, ROC

2 Institute of Atmospheric Science, National Central University, Chung-Li, Taiwan, ROC

* Corresponding author address: Prof. Tang-Huang Lin, College of General Education, Aletheia University, Tamsui, Taiwan, ROC; E-mail: thlin@csrsr.ncu.edu.tw
} 
quality. The automatic sun-tracking photometer CE318-2, manufactured by Cimel Inc. of France is equipped with eight standard filters (centered at 440, 670, 870, 936, $1020 \mathrm{~nm}$ and three $870 \mathrm{~nm}$ polarized filters), and provides measurements in the aerosol optical depth (AOD), precipitable water content, and sky radiance. After conducting corrections affected by the atmospheric absorption and the Rayleigh scattering effect, the AOD for the four filters at 440, 670, 870, and $1020 \mathrm{~nm}$ can be calculated from the sun photometer measurements (Holben et al. 1998). By using actual aerosol optical depth (AOD) data from ground-based sun photometers, the regional aerosol optical depth can be calculated from remotely sensed data (Tanre et al. 1988; Holben et al. 1992; Sifakis and Deschamps 1992; Liu et al. 2002; Lin et al. 2002). This information aids in the procedures for the atmospheric corrections of remotely sensed images, and provides data regarding the air quality. As long as the particle size distribution and aerosol optical depth are known, the atmospheric turbidity, which corresponds to the concentration of aerosols within the atmosphere, can be calculated using the turbidity law (Ångström 1929). However, because of the complex nature of aerosols, (Cachorro et al. 1987), without actual data, it is extremely difficult to calculate the particle size distribution merely with a simple physical model. Consequently, this paper tries to analyze and classify the characteristics of aerosols from actual ground measured data by introducing an effective parameter of the aerosol size distribution (effective aerosol size coefficient) to serve as an indicator in the monitoring of atmospheric turbidity. The introduction of an effective aerosol size distribution proves to be extremely stable, with its seasonal changes being below $5 \%$ under normal atmospheric conditions. This effectively overcomes the drastic changes brought forth when analyzing the particle size distribution.

\section{METHODOLOGY}

From the Ångström turbidity formula:

$$
\tau_{a \lambda}=\beta \lambda^{-\alpha},
$$

where $\tau_{a \lambda}$ is the aerosol optical depth, $\lambda$ is the wavelength, and $\beta$ is the Ångström turbidity coefficient which owns a positive correlation with the atmospheric turbidity. The higher the turbidity, the more aerosols present in the atmosphere, where it usually has a value roughly between 0 0.5. $\alpha$ is used to describe the size and distribution of aerosols. The lower the value of $\alpha$, the higher the proportion of bigger particles and vice versa. The value of $\alpha$ is normally between $0 \sim 4$. The closer it is to four, the more Rayleigh scattering present; and the closer it is to zero the more Mie scattering present. Due to the complex particle constituents and its spatial and temporal concentrations, the coefficients of the aerosol size distribution may differ greatly between local areas. Information on the aerosol optical depth can be acquired from satellite data, and if coupled with the local area particle size distribution, the atmospheric turbidity can thus be retrieved.

For the purposes of this study, calculation of the local particle size distribution was performed by obtaining data from the sun photometer from May to August 1998. In this way, the 
aerosol size distribution coefficient $\alpha$ could be analyzed. The sun photometer was installed on the roof of a four-story building at the National Central University campus in Taiwan to serve as one of the AERONET's (AErosol RObotic NETwork) observation sites. Due to the fact that the composition of air particles is subject to various influences, such as differing weather patterns, atmospheric circulations and local environmental conditions, the value of $\alpha$ is not always a constant (Cachorro et al. 1987). Figure 1 shows that the aerosol particle size distribution coefficient- $\alpha$, cannot be easily delineated by a physical or mathematical model because of its complex fluctuations with time. Therefore, this paper attempts to overcome this difficulty by combining the $\alpha$ value with the wavelength, or in other words, using the $\lambda^{* *}(-\alpha)$ term in describing the local aerosol particle coefficient. With the problem simplified, a more stable coefficient could theoretically be derived for Taiwan in each season. The procedure is first done by calculating the $\alpha$ and $\beta$ coefficients of the Ångström turbidity formula [Eq. (1)] with measurements from the sun photometer (at 440, 670, 870, $1020 \mathrm{~nm}$ ). Afterwards, the AOD in the bandwidth of 500 590 nm (SPOT/HRV/XS1) are integrated. From the scatter plot

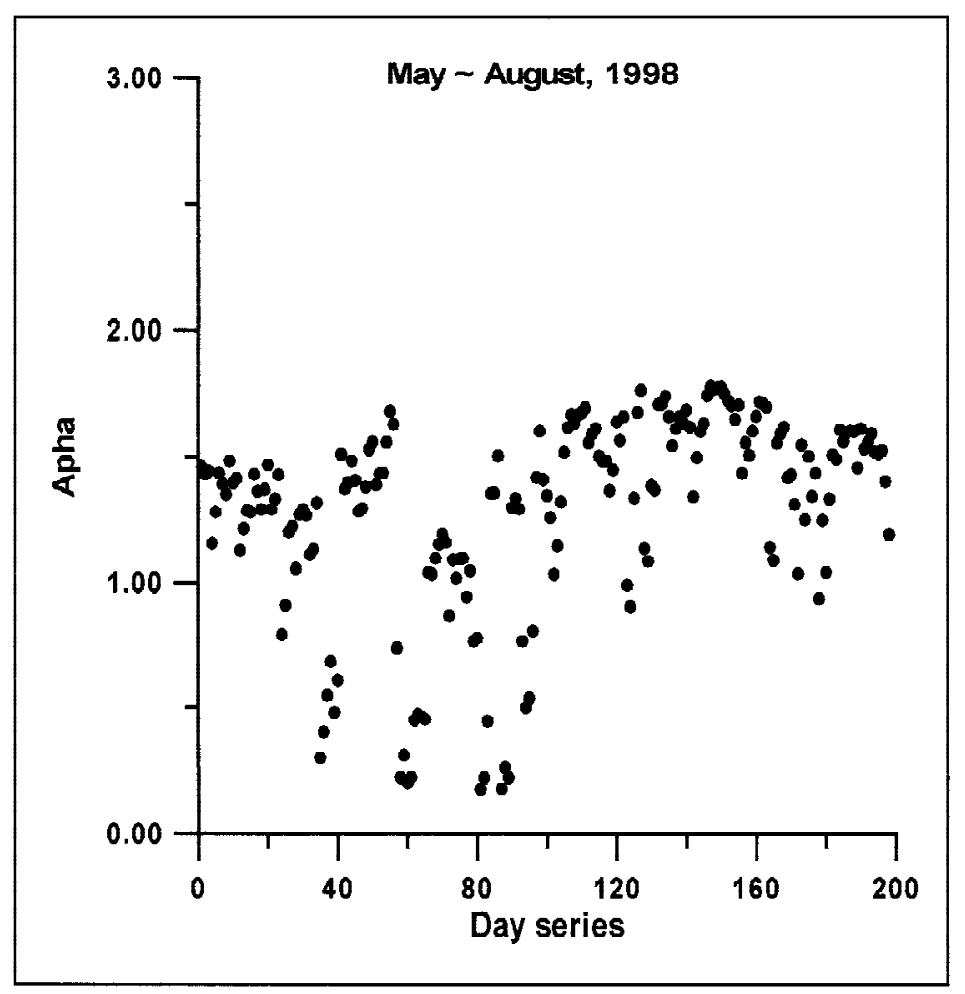

Fig. 1. The variation of the $\alpha$ coefficient retrieved by the ground-based sun photometer at the NCU Taiwan station of AERONET from May to August in 1998. 
(see Fig. 2a), it can be seen that the extent of the atmospheric turbidity increases with the aerosol optical depth, illustrating a cone shaped distribution, where a linear relationship clearly exists. The correlation coefficient reaches 0.96 (e.g., $0.93 * * 0.5$ ). By using a linear regression model, the average $\alpha$ value reaches 1.33, which is extremely close to the value of 1.3 suggested by Ångström, indicating that the atmospheric conditions during the research period were in a normal state.

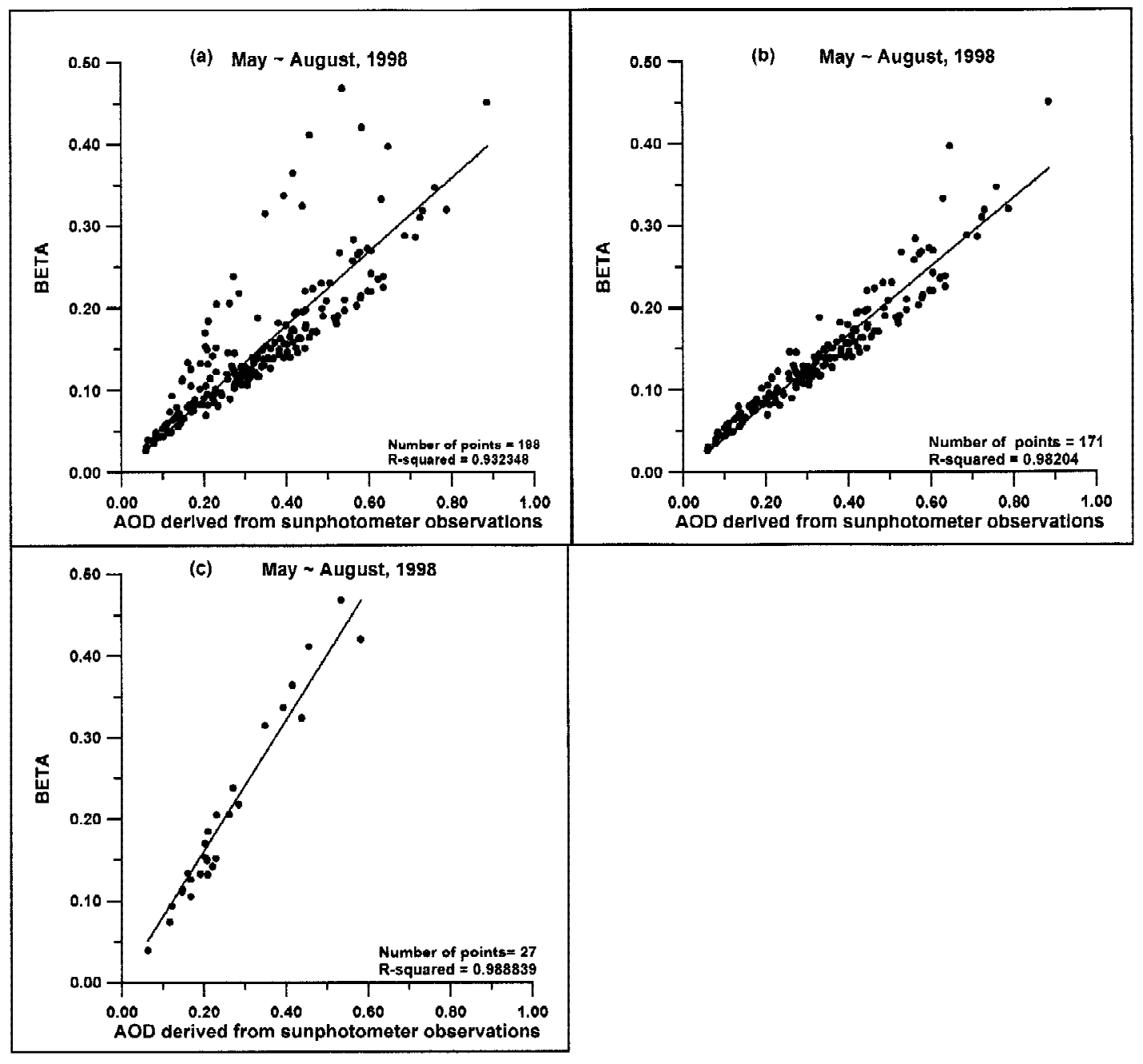

Fig. 2. (a)The relationship between the Ångström turbidity coefficient (BETA) and AOD in SPOT/HRV/XS1 bandwidth (500 590 nm) derived from the data set in Fig. 1. (b) Portion of smaller particles in figure (a), about $86 \%$ of the total amount of particles. (c) Portion of larger particles in figure (a), about $14 \%$ of the total amount of particles. 
Furthermore, the distribution of Fig. 2a shows that the average particle size can be split into two classes. An $\alpha$ value of 0.8 (the mean value adds one standard deviation of the dataset used in Fig. 2a) is used for categorizations of large and small particle sizes. The AOD is positively proportional with the atmospheric turbidity, where the R-squared value can be over 0.98 as shown in Figs. $2 \mathrm{~b}$, c. Figure $2 \mathrm{~b}$ shows that the average smaller aerosol particles accounts for $86 \%$ of the entire dataset, where the average $\alpha$ value is roughly 1.44 . The $\alpha$ value can be used in representing the aerosol particle coefficient of the test area, and the regression line can be employed in calculating the atmospheric turbidity. Figure $2 \mathrm{c}$ represents the average larger particles occupying the remaining 14\%, with the average $\alpha$ value being 0.36 . As the observational period occurred from May to August, the summer weather pattern was the dominant feature over Taiwan. Thus, the larger particles present, originated mostly from haze, cloud droplets or possibly from the Mongolian sandstorms, which explains the lower percentage $(14 \%)$. This should be considered a special case instead of the norm. If more long-term data can be collected, it would further improve the calculation of the atmospheric opacity and the local aerosol particle coefficient.

From the research results, a good linear relationship clearly exists between the aerosol optical depth in the SPOT HRV/XS1 bandwidth and the atmospheric turbidity. An effective aerosol size coefficient $A$ is thus defined in this paper as:

$$
A=1 /\left[\lambda^{* *}(-\alpha)\right] .
$$

Accordingly, the atmospheric turbidity can be calculated by the aerosol optical depth. Thus, the Ångström turbidity equation can be rewritten as:

$$
\beta=A \tau_{a \Delta \lambda},
$$

where $\mathrm{A}$ is the effective aerosol size coefficient and $\tau_{a \Delta \lambda}$ is the respective bandwidth ( $\left.\Delta \lambda\right)$ of the aerosol optical depth. Since the $\alpha$ value varies strongly both spatially and temporally, it is not easy to select an appropriate area for representation. But from Figs. 2b, c, the aerosol optical depth and turbidity coefficient demonstrates a positive proportional relationship; implying the effective aerosol size coefficient $\mathrm{A}$ is quite stable. If a representative local aerosol particle size parameter can be formed, and is employed along with satellite data in calculating the atmospheric turbidity from the aerosol optical depth, real time data on the air quality can be provided. Therefore, in the next section, long-term sun photometer observational data will be analyzed to try to form a local particle size parameter.

\section{DATA ANALYSIS AND DATABASE CONSTRUCTION}

As the origin and composition of aerosols are easily affected by weather patterns and atmospheric circulations, regional factors come into play. Moreover, aerosol composition and origin also varies seasonally necessitating the construction of a seasonal particle size param- 
eter for remote sensing data applications. With this in mind, analyses are made on all the observational data taken from the ground-based sun photometer, since it began operation at the Center for Space and Remote Sensing Research at the National Central University starting from April in 1998 to May of 2001. It is hoped that through the analysis of the three-year long observational data set, a representative particle size parameter of aerosols over the Chungli area (location of the university) can be constructed throughout each season, which in turn can be applied to the calculation of the atmospheric turbidity, and ultimately in the monitoring of the air quality via satellite data. This is done by first calculating the turbidity coefficient $\beta$ for each time point from turbidity equation (1) by using the AOD data retrieved from each filter $(440,670,870$ and $1020 \mathrm{~nm})$ of the sun photometer. In addition, the aerosol optical depth of the SPOT HRV/XS1 bandwidth must be calculated from the sun photometer data. It should be noted that the AOD of the SPOT HRV/XS1 bandwidth can not be directly measured from the sun photometer data. Instead, the AOD value of the SPOT HRV/XS1 spectral band is obtained by integration within the $500-590 \mathrm{~nm}$ bandwidth, as mentioned in Section 2. From equation (3), if the turbidity and the aerosol optical depth are directly proportional with each other, the effective particle size coefficient of regional aerosols can thus be constructed. Figure 3 illustrates the distribution pattern of the turbidity and aerosol optical depth from 1998 to 2001. In addition to displaying a fine linear relationship for each graph (the R-squared values are all above 0.91), in the distribution pattern of 1998, and 1999, two separate types can be witnessed, implying the existence of two distinct aerosol classes.

In order to analyze the aerosol characteristic for each respective season, the observational data were divided into four periods: 1) March to May for spring; 2) June to August for summer; 3) September to November for fall; 4) December to February for winter. However, data are not received during the winter period due to routine calibrations of the instrument. The distribution pattern of the turbidity and AOD of each season in each year once again demonstrates the fine linear relationship characteristic. For example, in the springtime of 1999 and 2001, and the fall period of 2000, there is virtually no existence of any significantly larger aerosol particles. If an $\alpha$ value of 0.8 is used for classification (roughly equal to one standard deviation), except for a lower R-squared value of 0.973 in the summer of 1998, the remaining values were all above 0.987 , indicating a directly proportional relation (Figs. 4, 5 and 6 show the classification results for each different particle in each season). The obtained effective aerosol size coefficient (A) of the SPOT HRV/XS1 bandwidth for each season is shown in Table 1. From the table, in 1998 and 2000, the largest variation of the particle parameter for each season is roughly $10 \%$ and $9 \%$ throughout the three-year average, suggesting fluctuations in the atmosphere. This is most notable in the summer and fall seasons of 1998 and the spring and summer seasons of 1999. Such fluctuations may have been caused by anomalistic weather phenomena, such as the Meiyu seasons or sandstorm events. The Meiyu phenomenon is a rainy season that occurs in East Asia during the spring due to the meeting of the prevailing winter northeastern monsoon winds and the summer prevailing southwestern monsoon winds forming a stationary frontal system. In 1999, the largest variation merely reached 3\%, indicating a more stable atmosphere. In addition to the larger seasonal variations, the remaining changes in the particle parameter of each season were not big, generally below $5 \%$. This means that with the exception of anomalous weather phenomena, these results can be used in repre- 
senting the seasonal aerosol particle parameter. However, in the longer term, more data must be continuously collected and analyzed to further improve the applicability and representation of the particle parameter. Although the results mentioned above do exhibit differences in each season, they were conducted from actual ground observations indicating that aerosol particle parameters do change seasonally, especially during the Meiyu seasons or sandstorms events.

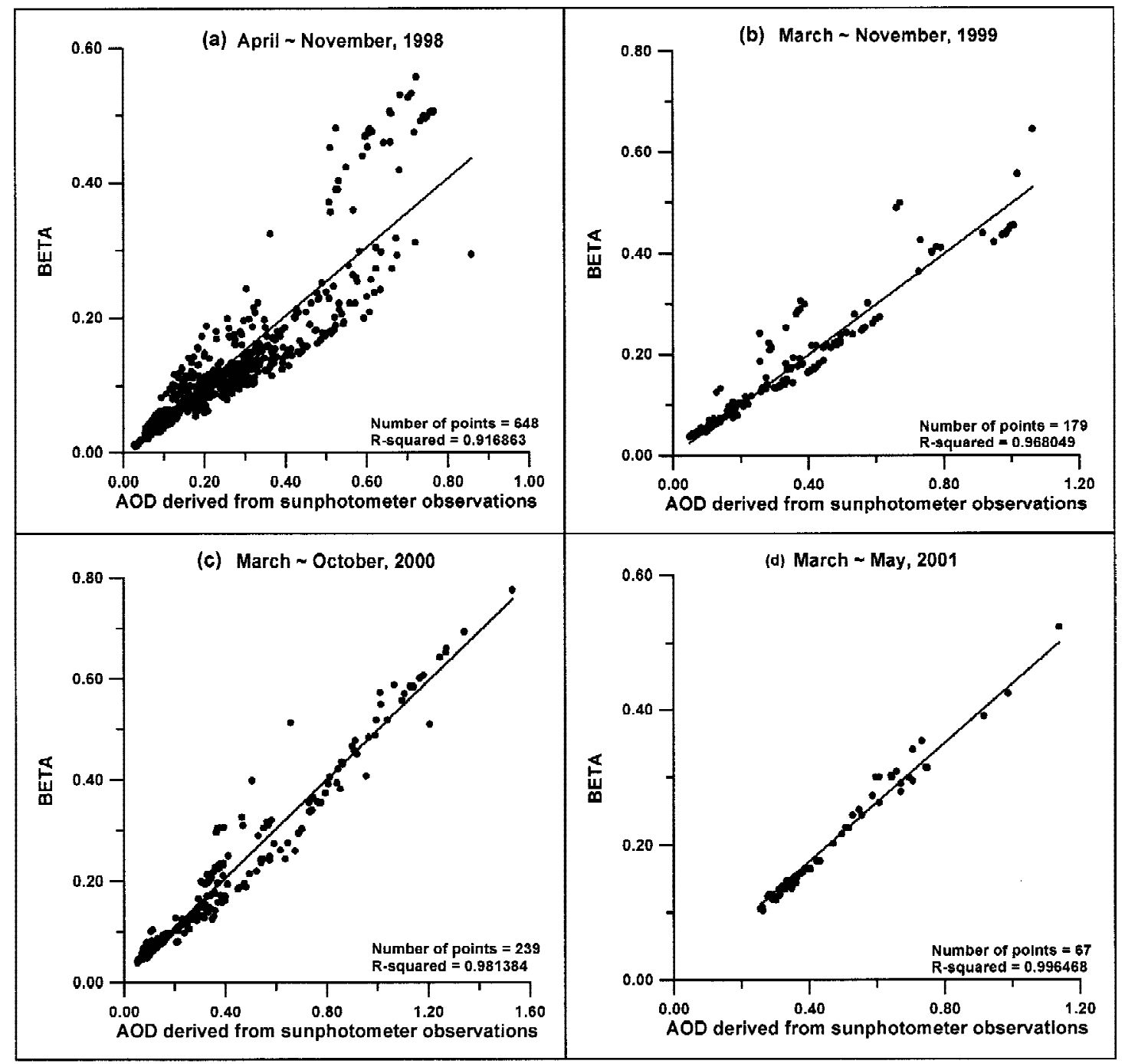

Fig. 3. The relationships between BETA and the AOD in the SPOT/HRV/XS1 bandwidth derived from the data sets collected by the ground-based sun photometer at NCU Taiwan station of AERONET. (a) from April to November in 1998, (b) from March to November in 1999, (c) from March to November in 2000, (d) from March to May in 2001. 
In addition to the analysis and database construction of the aerosol average particle parameter, this paper also explores the distribution pattern of the two aerosol size classes from the sun photometer observations in order to better understand how particle size varies and distributes. Taking the spring season of 1998 as an example, from the two classes shown in Fig. 4, both larger and smaller aerosol particles were arbitrarily chosen on April 17 and April 24. After calculating the aerosol particle size layout $(0.05 \sim 15$ micron $)$ via the method from

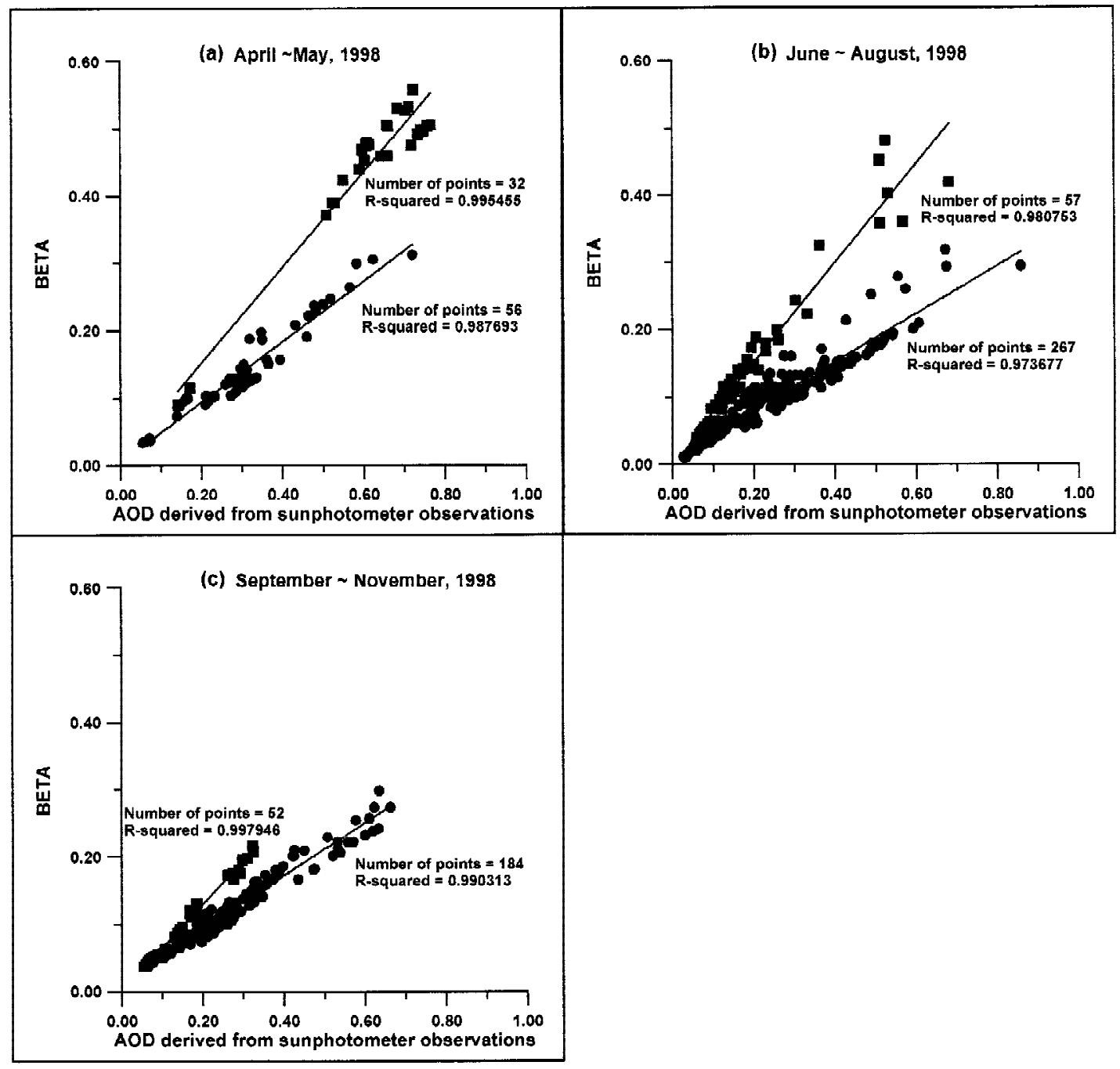

Fig. 4. The BETA distributions of each season of 1998 with the AOD in SPOT/ HRV/XS1 bandwidth. The red dots and blue diamonds represent the small and large particle parts, respectively: (a) spring (b) summer (c) fall. 
Dubovik et al. (2000) (see Fig. 7a), the results indicated that on April 17, the particle size increased significantly to $0.6 \sim 7$ micron, and on April 24, except for a small amount of particles centered around 0.1 0.3 micron, the remaining particle size distributions were quite stable. The calculation results for the summer and fall seasons during 1998 are shown in Figs. 7b, c, respectively. They are considered more stable when compared with the spring period. If comparisons are made with the particle size distribution throughout the six days, it is

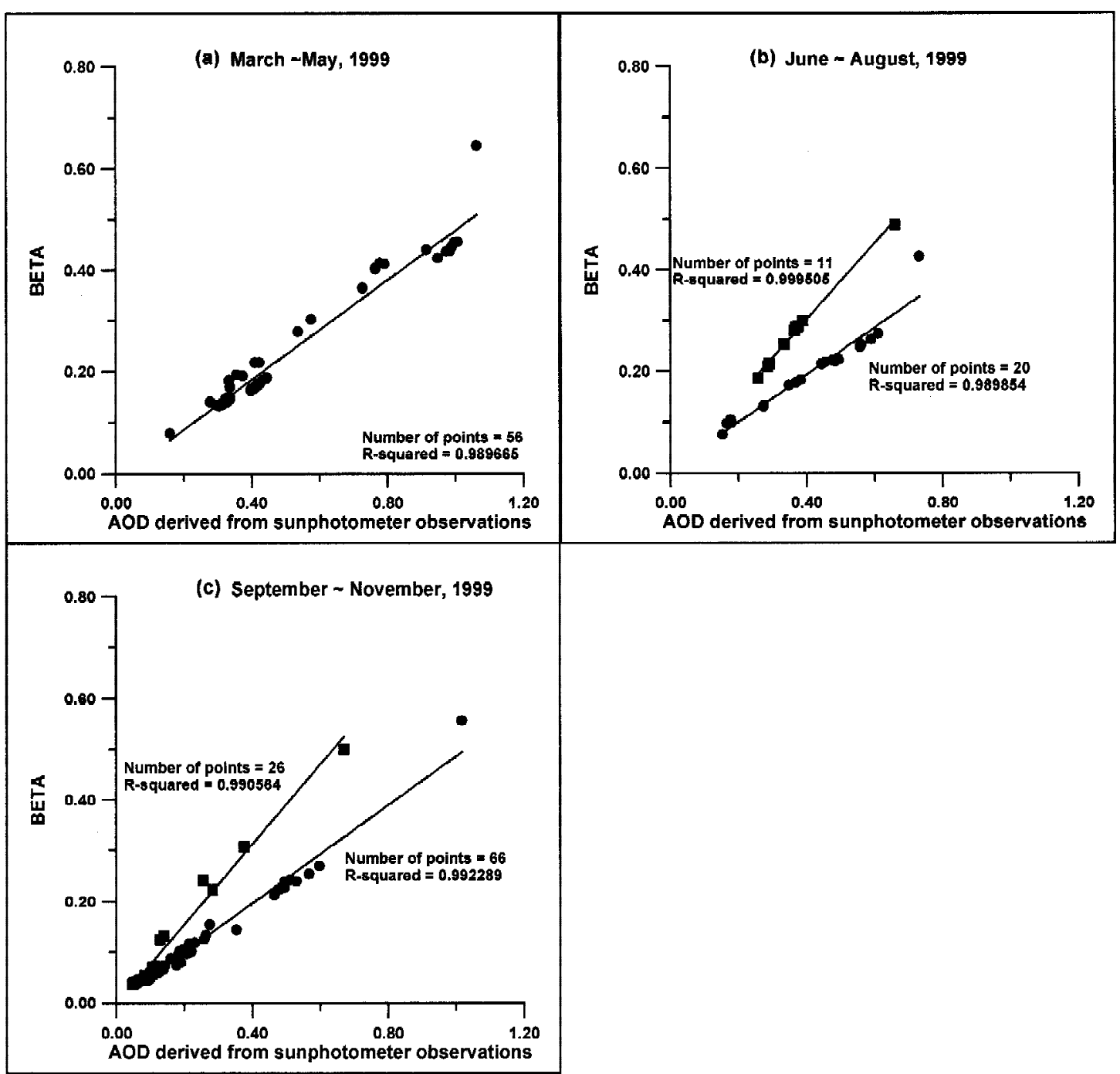

Fig. 5. Same as Fig. 4, but in the year 1999. 
discovered that except for the dates in April, a similar pattern also exists for the lesser amount of aerosols that are between 0.3 1.0 micron. The Aerosol Index (AI) derived by data from the Earth Probe Total Ozone Mapping Spectrometer (TOMS) (Torres et al. 1998) provides global sandstorm and biomass burning information (http://TOMS.gsfc.nasa.gov). From the TOMS' aerosol index, on April 17 a sandstorm originating from China moved eastward toward the Korean peninsula, which subsequently affected the areas of Korea, Japan and Taiwan (Fig. 8).

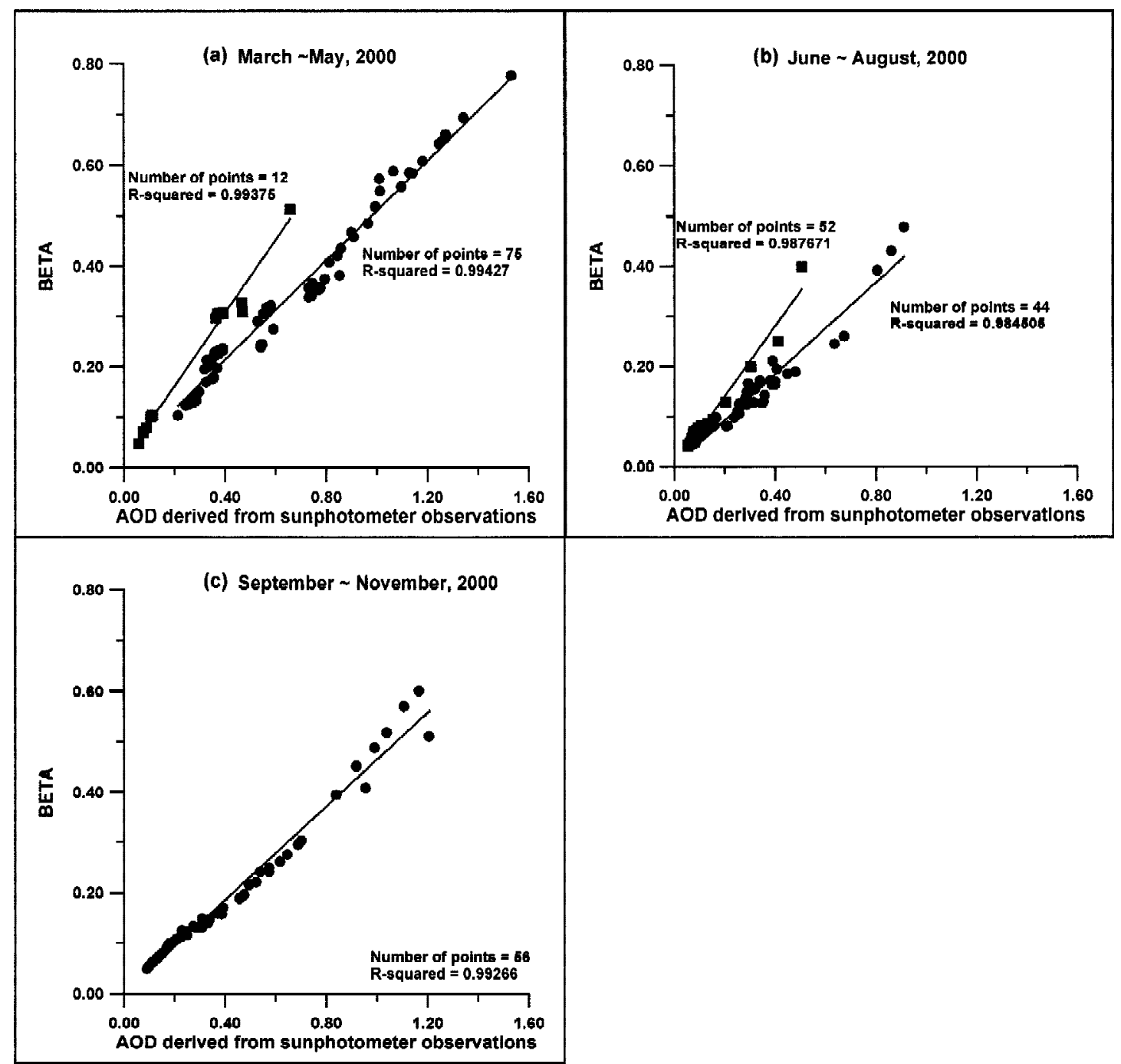

Fig. 6. Same as Fig. 4, but in the year 2000. 

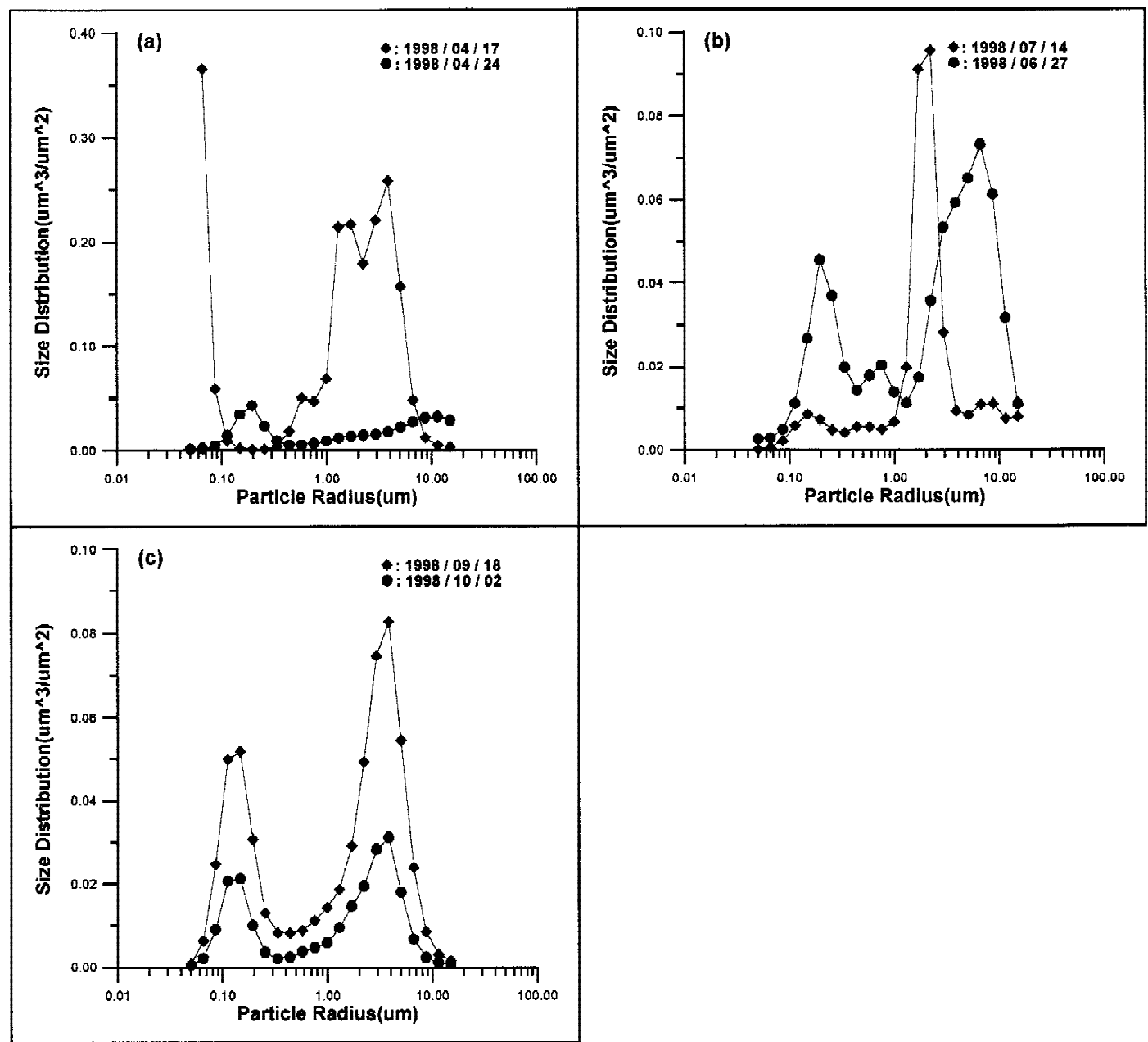

Fig. 7. (a) The particle size distributions of April 17 and 24 in 1998, which illustrates larger (diamond) and smaller (circle) types respectively; (b) The particle size distributions of June 27 and July 14; (c) The particle size distributions of September 18 and October 2.

The eastward movement of the sandstorm (Fig. 8a) caused a drastic increase in the concentration of suspended particles in the atmosphere around the Taiwan area. This trend can be witnessed from the particle size distribution results on April 17th. On the other hand, the particle size distribution on April 24 returned back to normal after the effect from the sandstorms had passed (Fig. 8b). From the above results, the abnormal particle size distribution pertains to the sandstorm event of April 17. The pattern over the remaining four days is considered a more typical aerosol distribution over Northern Taiwan. 
(a)

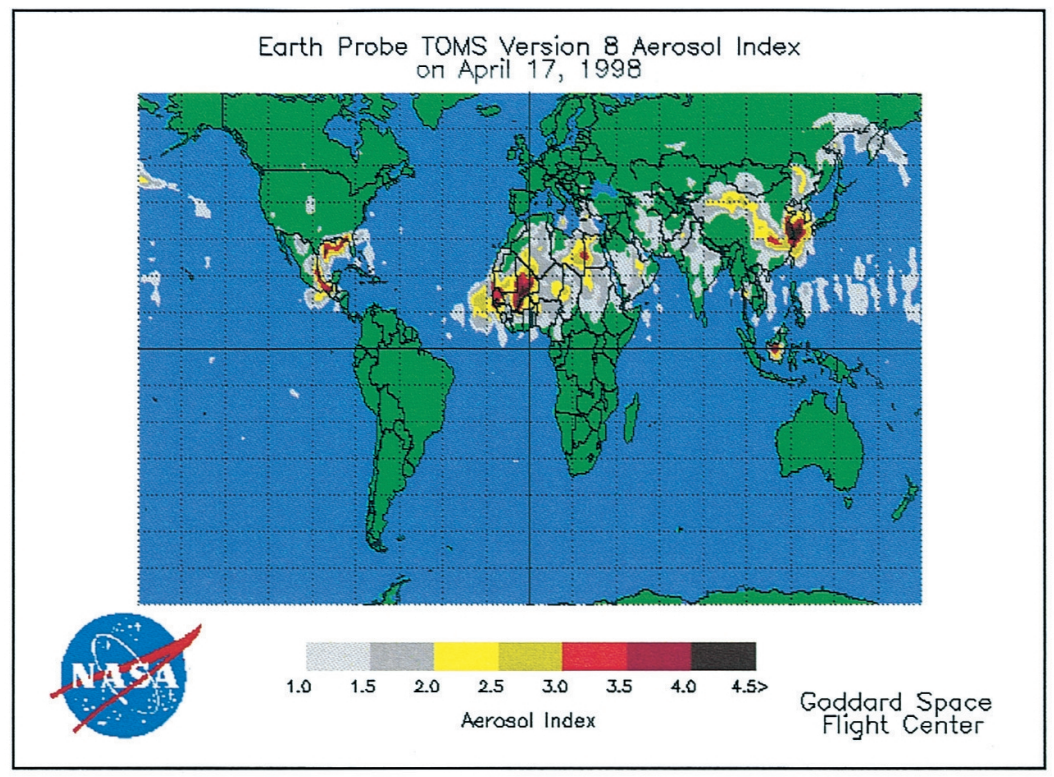

(b)

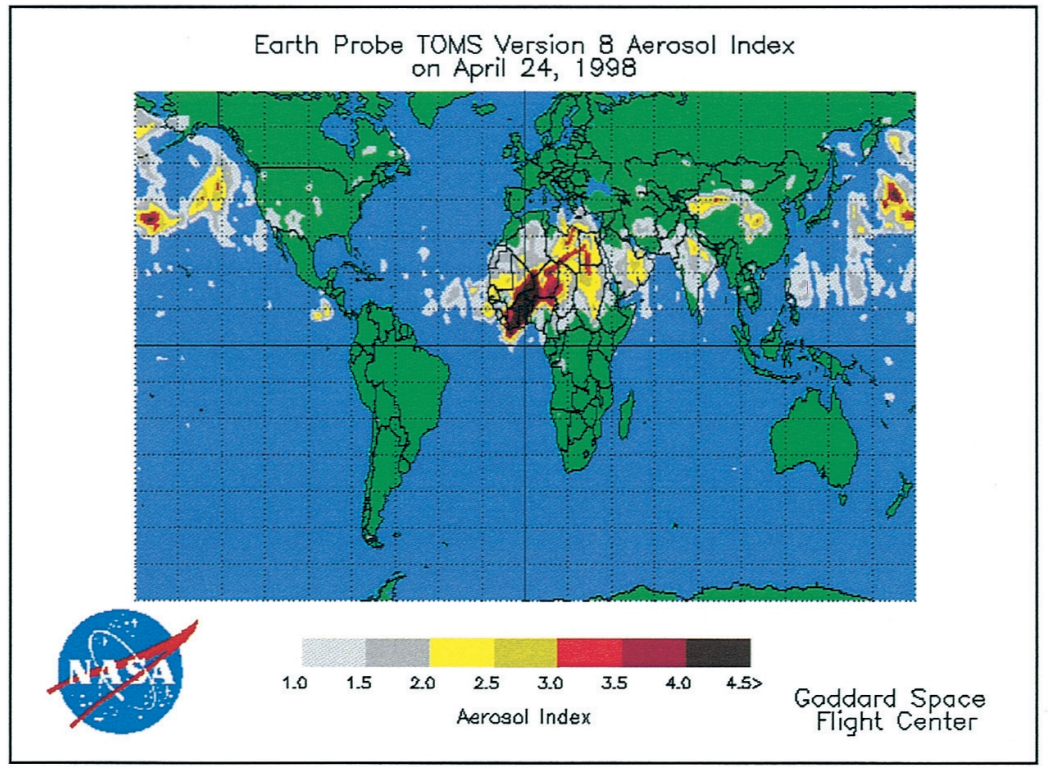

Fig. 8. The distribution of the Aerosol Index from the Earth Probe TOMS data from http://TOMS.gsfc.nasa.gov, (a) April 17, 1998, (b) April 24, 1998. 


\section{A CASE STUDY IN THE ATMOSPHERIC TURBIDITY RETRIEVAL}

Figure 9a is a color image acquired on June 27, 1998 by the SPOT HRV sensor. The location is the Chungli area of northern Taiwan. This area contains cities, villages, industrial parks, farmland, ponds and other land cover types within an image size of 1024 by 1024 . By first using the AOD calculation model developed by Lin et al. (2002) to obtain the AOD distribution, and using an effective aerosol size coefficient $(A)$ of 0.387 (Table 1), the distribution pattern of the atmospheric opacity can be obtained as shown in Fig. 9b. From the figure, higher turbidity is located at areas near the city and the two industrial parks. Other regions such as villages do not show such a high value, indicating that when the satellite image was taken, the air quality was poorer over the cities and industrial parks. This reasonable distribution showcases the feasibility of using satellite data in the monitoring of the air quality.

On the other hand, the topic of radiative forcing, when considering the effect of aerosol loading has received a lot of attention in recent years. The most important factors with regards to aerosols are their optical properties and size distributions. The properties of sulfate aerosols have been successfully parameterized with the growth factor by Li et al. in 2001. One of the most important variables for the aerosol size distribution is the effective radius, which can be calculated from the Junge size distribution n(r) (Junge 1963):

$$
n(r)=\frac{d N}{d r}=C(z) r^{-(v+1)}
$$

Table 1. The database of the effective aerosol size coefficient in SPOT/HRV/ XS1 bandwidth calculated from the measurements of the ground-based sun photometer at NCU Taiwan station of AERONET from spring 1998 to 2001 .

\begin{tabular}{ccccccccc}
\hline & \multicolumn{2}{c}{$\begin{array}{c}\text { Spring } \\
\text { Mar } \sim \text { May }\end{array}$} & \multicolumn{2}{c}{$\begin{array}{c}\text { Summer } \\
\text { Jun } \sim \text { Aug }\end{array}$} & \multicolumn{2}{c}{$\begin{array}{c}\text { Fall } \\
\text { Sep Nov }\end{array}$} & \multicolumn{2}{c}{$\begin{array}{c}\text { Average } \\
\text { Mar Nov }\end{array}$} \\
\cline { 2 - 10 } & $\begin{array}{c}\text { Lager } \\
\text { particle }\end{array}$ & $\begin{array}{c}\text { Smaller } \\
\text { Yearticle }\end{array}$ & $\begin{array}{c}\text { Lager } \\
\text { particle }\end{array}$ & $\begin{array}{l}\text { Smaller } \\
\text { particle }\end{array}$ & $\begin{array}{c}\text { Lager } \\
\text { particle }\end{array}$ & $\begin{array}{c}\text { Smaller } \\
\text { particle }\end{array}$ & $\begin{array}{c}\text { Lager } \\
\text { particle }\end{array}$ & $\begin{array}{c}\text { Smaller } \\
\text { particle }\end{array}$ \\
\hline 1998 & 0.725 & 0.458 & 0.751 & 0.387 & 0.649 & 0.439 & 0.722 & 0.417 \\
1999 & -- & 0.471 & 0.753 & 0.479 & 0.776 & 0.491 & 0.765 & 0.476 \\
2000 & 0.765 & 0.514 & 0.701 & 0.460 & -- & 0.464 & 0.769 & 0.497 \\
2001 & -- & 0.439 & -- & -- & -- & -- & -- & 0.439 \\
Average & 0.745 & 0.471 & 0.735 & 0.442 & 0.713 & 0.465 & 0.752 & 0.457 \\
\hline
\end{tabular}

'--': absent data. 
(a)

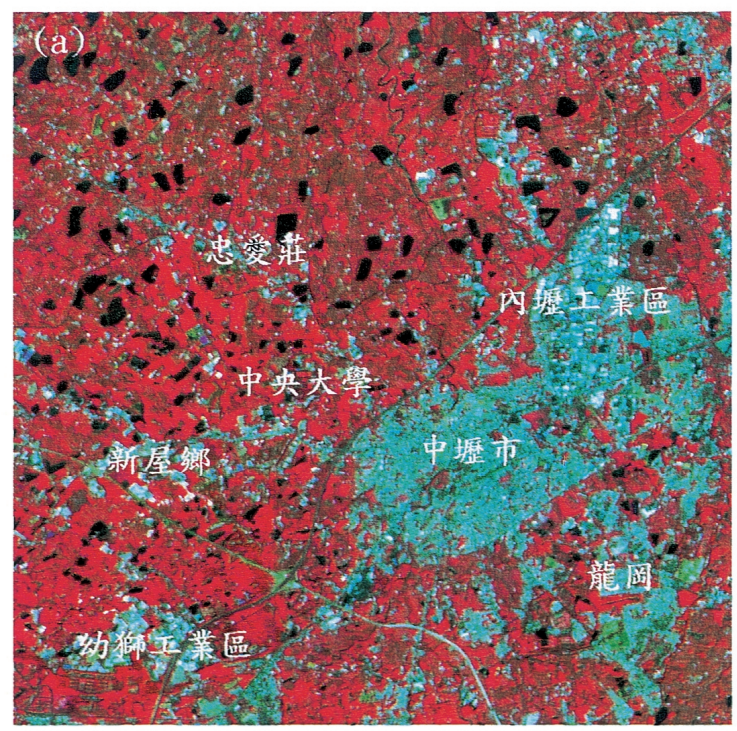

(b)

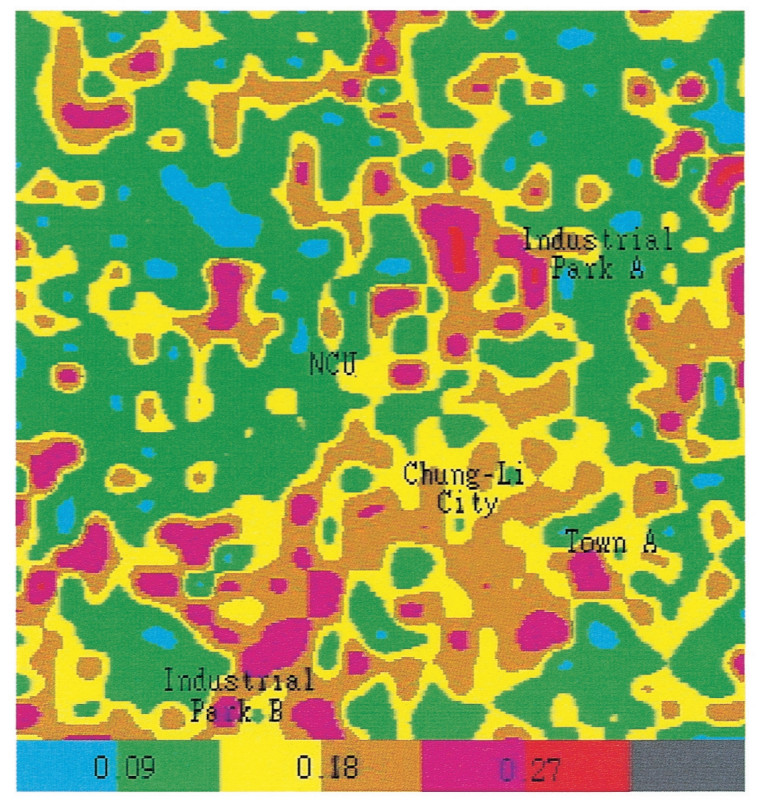

Fig. 9. (a) Color image of SPOT/HRV (B: XS1; G: XS2; R: XS3) of Chungli area acquired on June 27, 1998. (b) The BETA $(\beta)$ distribution retrieved from Figure (a). 
where $\mathrm{N}$ is the number density, $\mathrm{r}$ is the radius and $\mathrm{C}(z)$ is a factor proportional to the aerosol concentration, which is dependent on the altitude $z$ (Biggar et al. 1990). Through the relationship $v=\alpha+2$ (Iqbal 1983; Bruegge et al. 1992), the exponent $v$ can be obtained from the value of $\alpha$, which can be estimated from equation (2). This produces a high possibility for the effective radius of all the aerosols within the column (not only the sulfate aerosols) to be delineated by the effective aerosol size coefficient $(A)$ constructed in this study. However, more examinations and formulations are needed for its actual application in climate models.

\section{CONCLUSION}

By using three years of data in analyzing the characteristics of the aerosol size parameter over the Chungli area for each season (1998 2001), a stable and representative effective aerosol size coefficient database was constructed. Except for seasons influenced by anomalous weather phenomena, most of the seasons were stable and the particle parameter highly applicable. Consequently, excluding special situations, this approach seems plausible in supplying information regarding the atmospheric turbidity via satellite data in a quick and effective manner. Data should continue to be collected and analyzed so that the particle size coefficient database can be maintained and updated to improve its applicability.

Acknowledgements The authors thank the team of AERONET (GSFC NASA, USA) for their data providing. The research was supported by the National Science Council of Taiwan.

\section{REFERENCES}

Ångström A. K., 1929: On the atmospheric transmission of sun radiation and on dust in the air. Geogr. Ann., 11, 156-166.

Biggar, S. F., D. I. Gellman, and P. N. Slater, 1990: Improved evaluation of optical depth components from Langley plot data. Remote Sens. Environ., 32, 91-101.

Bruegge, C. J., R. N. Halthore, B. Markham, M. Spanner, and R. W. Wrigley, 1992: Aerosol optical depth retrievals over the Konza prairie. J. Geophys. Res., 97, 18743-18758.

Cachorro, V. E., A. M. de Frutos, and J. L. Casanova, 1987: Determination of the Ångström turbidity parameters. Appl. Opt., 26, 3069-3076.

Dubovik, O., A. Smirnov, B. N. Holben, M. D. King, Y. J. Kaufman, T. F. Eck, and I. Slutsker, 2000: Accuracy assessment of aerosol optical properties retrieval from AERONET sun and sky radiance measurements. J. Geophys. Res., 105, 9791-9806.

Iqbal, M., 1983: An introduction to solar radiation. Academic Press.

Junge, C. E., 1963: Air chemistry and radiochemistry. Academic Press.

Li, J., J. G. D. Wong, J. S. Dobbie, and P. Chylek, 2001: Parameterization of the optical properties of sulfate aerosols. J. Atmos. Sci., 58, 193-209.

Lin, T. H., A. J. Chen, G. R. Liu, and T. H. Kuo, 2002: Monitoring the Atmospheric Aerosol Optical Depth with SPOT Data in Complex Terrain. Inter. J. Remote Sens., 23, 647-659. 
Liu, G. R., A. J. Chen, T. H. Lin, and T. H. Kuo, 2002: Applying SPOT Data to Estimate the Aerosol Optical Depth and Air Quality. J. Environ. Modeling Software, 17, 3-9.

Holben B. N., E. Vermot, Y. J. Kaufman, D. Tanre, and V. Kalb, 1992: Aerosol retrieval over land from AVHRR Data-Application for atmospheric correction. IEEE Trans. Geosci. Remote Sens., 30, 212-222.

Holben, B. N., T. F. Eck, I. Slutsker, D. Tanre, J. P. Buis, A. Setzer, E. Vermote, et al., 1998: AERONET- a federated instrument network and data archive for aerosol characterization. Remote Sens. Environ., 66, 1-16.

Sifakis, N. I., and P. Y. Deschamps, 1992: Mapping of air pollution using satellite data. Photogram. Eng. Remote Sens., 58, 1433-1437.

Tanre, D., P. Y. Deschamps, C. Devaux, and M. Herman, 1988: Estimation of Saharan aerosol optical depth from blurring effects in Thematic Mapper data.J. Geophys Res., 93, 15955-15964.

Torres, O., P. K. Bhartia, J. R. Herman, and Z. Ahmad, 1998: Derivation of aerosol properties from satellite measurements of backscattered ultraviolet radiation. Theoretical Basis, J. Geophys. Res., 103, 17099-17110. 